Received: January 3, 2018

Revision received: February 21, 2018

\title{
Piano Performance and Psychological Control in Piano Teaching Based on Cognitive Psychology
}

\author{
Jinzhe Wang ${ }^{1}$ \\ Xi'an Conservatory of Music
}

\begin{abstract}
Piano teaching should follow the basic principles of cognitive psychology in order to understand the psychological state of students in the piano performance to help students in better psychological control. This paper analyzed the psychological phenomenon of students in the piano performance from the perspective of cognitive psychology, and conducted an in-depth analysis of the cultivation of piano performing skills, which is of great scientific and theoretical value and significance in educational practise for the piano teaching quality improvement.
\end{abstract}

\section{Keywords}

Cognitive Psychology $\bullet$ Piano Teaching $\bullet$ Piano Playing $\bullet$ Psychological Control

\footnotetext{
${ }^{1}$ Correspondence to: Jinzhe Wang (MA), Piano Department, Xi'an Conservatory of Music, Xi'an 710032, China. Email: jinzhewang@hotmail.com
}

Citation: Wang, J.J. (2018). Piano Performance and Psychological Control in Piano Teaching Based on Cognitive Psychology Educational Sciences: Theory \& Practice, 18(5), 1828-1835. http://dx.doi.org/10.12738/estp.2018.5.083 
In the piano teaching, some students are often too nervous to perform well or even "break down" during performance, while some ordinary students can give outstanding performance at stage and some are easily disturbed by external environment with poor performance. This reflects what we call "psychological quality". These cases show that in addition to skills in piano performance, self-psychological control ability is also important, which not only directly influences but also determines the former (Simones, Schroeder \& Rodger, 2015). In the process of piano teaching, teachers must explore and understand the status and role of good "psychological control" in "piano performance" through the principles of cognitive psychology (Bernal, 2018). Therefore, this paper focused on the psychological status of students during the piano performance from the perspective of cognitive science, so as to achieve better teaching effect and better psychological state of students during piano performance.

\section{Psychological analysis of piano teaching and piano performance}

Piano practice and performance involve both motor skills and mental skills. The training related to skill learning is based on the close connection between cognitive psychological system, perception system, and motor system. The learning of piano skills are divided into four stages: orientation, decomposition, integration, and proficiency. Because of complex and varied psychological states of the piano players in the four stages, various psychological factors are intertwined, interacted, restricted and interdependent. The study of piano playing skills is different from that of general knowledge in that the acquisition of piano skills begins at the orientation stage and ends at the proficiency stage, a spiralling dynamic process (Gelding, Thompson \& Johnson, 2015). Understanding of the psychological characteristics during the above stages in the piano practice process can serve as a theoretical guidance for choosing the correct learning method, cultivating a good habit of piano practice and improving the learning effect, and provides a powerful theoretical understanding and practice basis for deepening the reform of modern piano teaching.

\section{Analysis of psychological problems of students in piano playing}

Piano learning is a very long and arduous process, influenced by a variety of psychological factors such as perception, attention, emotion, will, musical thinking and personality. Most students will have some learninghindering psychological status, as shown in Table 1 (Zhou, 2017).

Table 1

Psychological Phenomena of Students during Piano Performance

\begin{tabular}{ll}
$\begin{array}{l}\text { Psychological } \\
\text { phenomenon }\end{array}$ & \multicolumn{1}{c}{ Performance aspects } \\
\hline $\begin{array}{l}\text { Inferiority and } \\
\text { fear }\end{array}$ & $\begin{array}{l}\text { To make low evaluation of personal ability and quality, feel inferior to others } \\
\text { everywhere, be pessimistic and disappointed, and often face setbacks in learning. } \\
\text { There is no assertiveness, lack of self-confidence, and people always want to rely on } \\
\text { Dependency } \\
\text { others and cannot be self-supporting or self-sufficient. The "one-to-one" teaching } \\
\text { style of piano teaching can easily encourage students' dependence psychology. }\end{array}$ \\
$\begin{array}{l}\text { Excessive stress, blank brains, fierce battle, hope to perform at super level, } \\
\text { Psychological } \\
\text { obstacles }\end{array}$ & $\begin{array}{l}\text { Overemphasizing the audience reaction, Fear of mistakes, always thinking about } \\
\text { mistakes that have occurred, Lack of desire to play, lack of concentration due to } \\
\text { excessive concentration, etc. }\end{array}$ \\
\hline
\end{tabular}




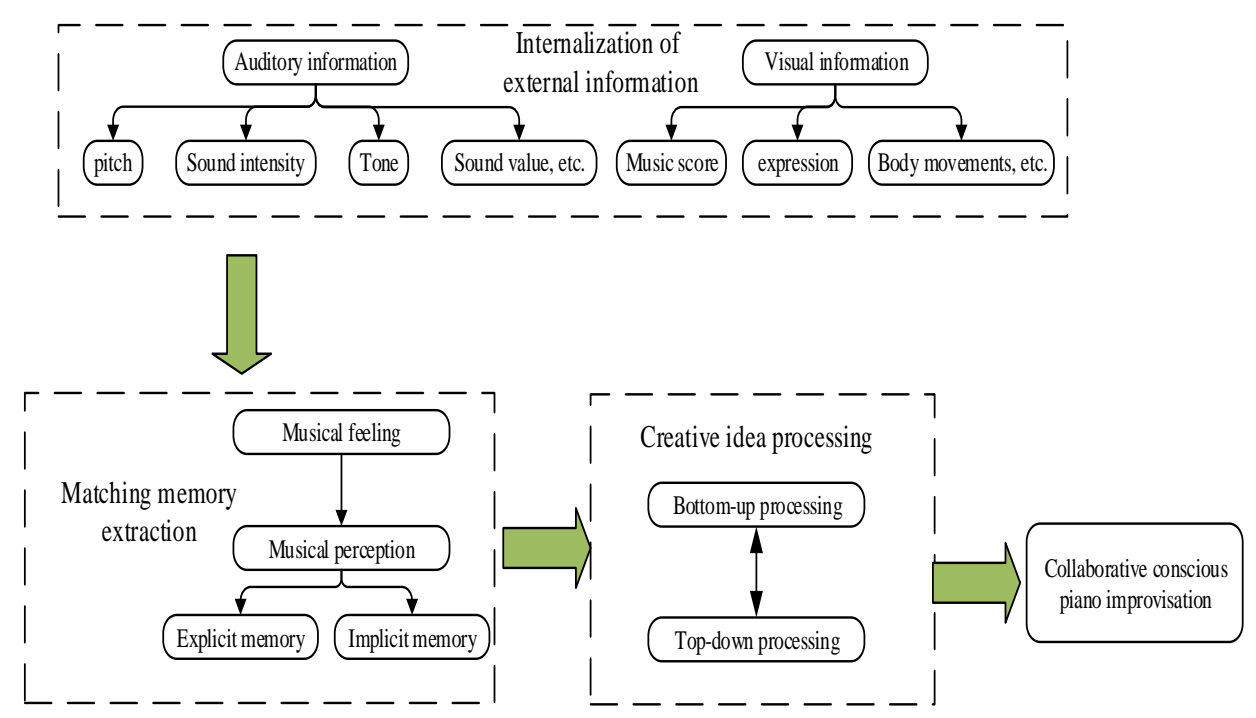

Figure 1. The thinking process of playing piano performance from the perspective of cognitive psychology.

Table 2

Analysis of Thinking Steps for Performers Performing Piano Performance based on Cognitive Psychology

\begin{tabular}{|c|c|c|}
\hline Stage & Level & Analysis \\
\hline \multirow[t]{2}{*}{$\begin{array}{l}\text { Internalization of } \\
\text { external } \\
\text { information }\end{array}$} & $\begin{array}{l}\text { Musical } \\
\text { feeling }\end{array}$ & $\begin{array}{l}\text { The direct reflection of the human brain on the specific } \\
\text { characteristics of pitch, intensity, timbre, and timbre of the music } \\
\text { object is the process by which the individual accepts basic musical } \\
\text { information from outside, and is also an important channel for the } \\
\text { individual to perceive and acquire music information. }\end{array}$ \\
\hline & $\begin{array}{l}\text { Music } \\
\text { awareness }\end{array}$ & $\begin{array}{l}\text { Deep music cognition based on a large number of musical } \\
\text { sensations. }\end{array}$ \\
\hline \multirow[t]{2}{*}{$\begin{array}{l}\text { Matching memory } \\
\text { extraction }\end{array}$} & $\begin{array}{l}\text { Implicit } \\
\text { memory }\end{array}$ & $\begin{array}{l}\text { The accumulation of implicit memory requires students to listen } \\
\text { more to various types of music, accumulate different auditory } \\
\text { sounds for different musical styles and accompaniment sound } \\
\text { patterns, and accumulate different sound effects for different } \\
\text { performance methods. }\end{array}$ \\
\hline & $\begin{array}{l}\text { Explicit } \\
\text { memory }\end{array}$ & $\begin{array}{l}\text { There is a need for conscious efforts to make the information } \\
\text { restored. Its influence on behavior is that the individual can realize. }\end{array}$ \\
\hline \multirow[b]{2}{*}{$\begin{array}{l}\text { Creative idea } \\
\text { processing }\end{array}$} & $\begin{array}{l}\text { Bottom-up } \\
\text { processing } \\
\text { mode }\end{array}$ & $\begin{array}{l}\text { Processes started with external stimuli, which first analyze the } \\
\text { smaller units of consciousness and then turn. To larger perception } \\
\text { units. The interpretation of musical sensory stimuli is achieved } \\
\text { through a series of interrelated processes. }\end{array}$ \\
\hline & $\begin{array}{l}\text { Top-down } \\
\text { processing } \\
\text { mode }\end{array}$ & $\begin{array}{l}\text { The subject begins to process the general knowledge of the } \\
\text { cognitive object, thereby forming a certain expectation and } \\
\text { hypothesis about the object of the thinking. This expectation and } \\
\text { assumption guides and constrains the level and direction of } \\
\text { subsequent music ideas at each stage. }\end{array}$ \\
\hline $\begin{array}{l}\text { Externalization of } \\
\text { the complete } \\
\text { music }\end{array}$ & \multicolumn{2}{|c|}{$\begin{array}{l}\text { Its presentation is constrained by the musical form of the performance object and } \\
\text { the music demand, and the ultimate goal is to set off the performance object. }\end{array}$} \\
\hline
\end{tabular}




\section{The Thinking Process of Piano Playing Performance based on the Perspective of Cognitive Psychology}

Piano performance is a comprehensive art that combines multi-disciplinary skills such as performance, harmony and music, which requires the player to create and present a piano performance that meets the psychological needs of expected music effect based on careful thinking and full preparation. The application of the cognitive psychology into analysis of piano performance can divide the whole process of piano editing and playing into the following four stages: internalization of external information, extraction of matching memory, processing of creative ideas, and externalization of complete music connotations. (see Figure 1) (Colombo \& Antonietti, 2017).

From the perspective of cognitive psychology, the thinking step and playing process of the player during the piano performance were analyzed, as shown in Table 2.

Piano performance emphasizes that the player must have a sufficient sense of collaboration, and can give appropriately personalized performance in the context of setting off the subject. Through the changes in rhythm, pitch, and even tonal changes, the sudden incidents on the scene can be handled (Eitel \& Scheiter, 2015). Therefore, the externalization of complete music connotations during the piano performance requires a player of a strong performance ability.

\section{Piano Performance in Piano Teaching based on Cognitive Psychology}

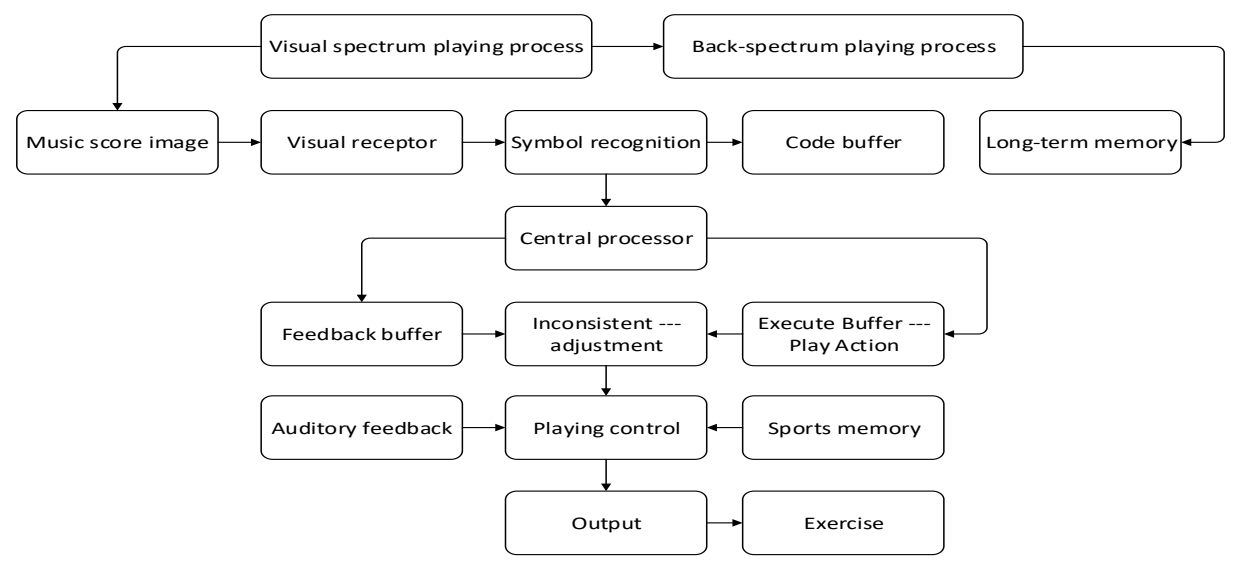

Figure 2. Psychology operating system of piano playing cognitive psychology model.

Research on piano performance from the perspective of cognitive psychology is a relatively common method in foreign countries. Because cognitive psychology mainly studies the process and characteristics of human cognition, it has a great influence on the field of education. In recent years, scholars have tried to understand and explain the particularity of piano performance more comprehensively by examining all aspects of piano performance. Since piano performance includes many task elements, such as note recognition and rhythm recognition, scholars generally believe that the cognitive mode of visual play is a complex mode with multiple levels and multiple latitudes. This model involves both special cognitive skills related to music and 
non-music cognitive skills, and is even influenced by many factors such as years of study, practice time and the utilization of relevant training strategies (MacRitchie, 2015). Therefore, the cognitive psychology mode of piano performance can be demonstrated in Figure 2.

In terms of the relationship between human and spectrum in the process of piano performance, according to the cognitive psychology, man is a unified and complex information processing system, and the connection between man and the outside world is actually the process that people obtain information from outside and then store, process, extract, and apply the information. The stave in music is a unique symbol system, and each symbol has an independent musical meaning (Pike, 2014).. Regarding the psychological cognitive mechanism in the piano performance, piano performance can only be accomplished under the dual effects of physiology and psychology. It involves psychological processes such as perception, instantaneous memory, attention, and short-term memory and long-term memory as a "special form of human cognitive process", detailed in Table 3.

Table 3

The Process of Psychological Recognition in the Process of Piano Performance

\begin{tabular}{ll}
\hline $\begin{array}{l}\text { Psychological Manifestations } \\
\text { process }\end{array}$ & Mans \\
\hline
\end{tabular}

$\begin{array}{ll}\text { process } & \text { Piano learning beginners often rely on sensory stimuli to perceive sensations when they } \\ \text { perceive musical scores. Some current teaching materials use different colors to indicate } \\ \text { different melody parts, which increases the amount of sensation stimuli and thus meets } \\ \text { the beginner's perception rules. } \\ \text { There is a pre-reading process in the piano performance, that is, the eye has scanned to } \\ \text { the next or several sounds while playing a sound. Through training, the speed of eye } \\ \text { movements of students can be increased to expand the amount of registration of feelings } \\ \text { instant } & \begin{array}{l}\text { After the individual completes the sensory registration, he must provide continuous } \\ \text { memory }\end{array} \\ \text { "attention" for about } 2 \text { seconds before he or she can input the stimulus information into } \\ \text { the short-term memory. }\end{array}$

As above, the process of piano performance and the influencing factors of each process are interpreted from the perspective of cognitive psychology, which is now simply illustrated as in Figure 3.

\section{Psychological Control in Piano Teaching based on Cognitive Psychology}

Piano performance relies on strong will and indomitable spirit to break through all technical difficulties. Players must realize that music performance is a noble art and put down all thoughts and distractions with full enthusiasm in music performances. They should focus all of energy on the musical performance and presentation, which is the only way to bring the piano performance to the artistic realm of perfection. However, the psychological quality of piano players directly affects the performance process and the effect of on-the-spot performance (Vandervert, 2016). The psychological qualities of the piano players include a combination of 
temperament, personality, emotional response, self-confidence, self-esteem, ambition, cognitive mode, and psychological endurance.

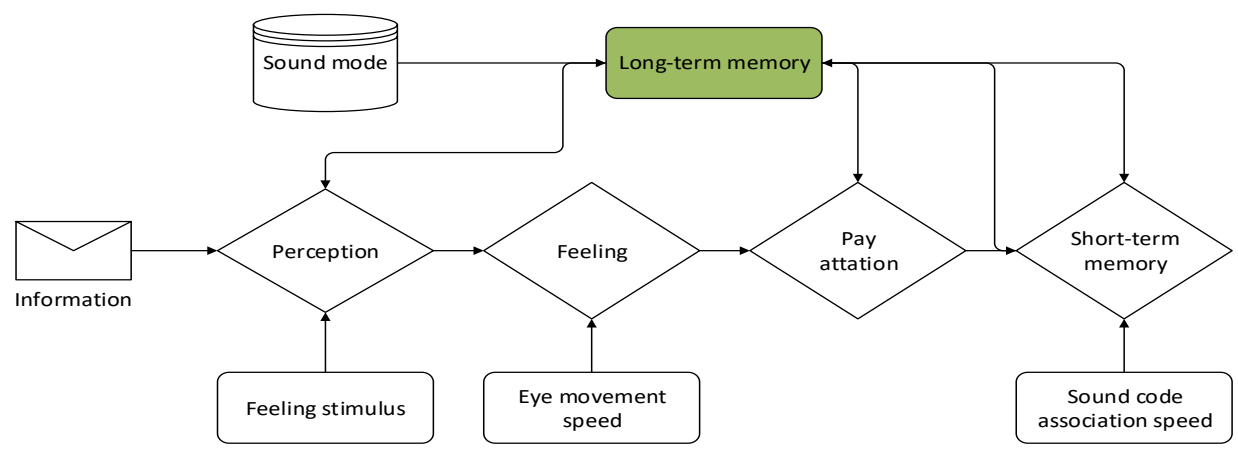

Figure 3. Program diagram of the piano playing process.

\section{Students' psychological control in the process of piano performance}

Piano players who want to improve their psychological quality must first improve their ability to adjust themselves. The psychological control skills required for performance are actually cultivated during the practice (Guven, 2017). The specific psychological control methods are shown in Table 4.

Table 4

Piano Player Psychological Control

\begin{tabular}{ll}
\hline Mental control & $\begin{array}{l}\text { Piano performance is the second creation of music. The performer uses his } \\
\text { skillful performance techniques and his deep understanding of the work. }\end{array}$ \\
$\begin{array}{l}\text { Maintain a good mood } \\
\text { and a harmonious unity } \\
\text { of mind and body }\end{array}$ & $\begin{array}{l}\text { Creatively exposing the work to the audience requires the close cooperation } \\
\text { between brain power, mental power, and ear power. Before the performance } \\
\text { or examination, we should strive to create a comfortable and natural state for } \\
\text { ourselves, and let ourselves be in a relatively stable state. }\end{array}$ \\
$\begin{array}{l}\text { In order to establish full self-confidence, this requires practitioners to strictly } \\
\text { meet their own requirements in the usual practice, and they must not have the } \\
\text { suild full confidence }\end{array}$ & $\begin{array}{l}\text { The signal to the audience is about to begin, so that the audience can quickly } \\
\text { calm down, give yourself a good playing environment }\end{array}$ \\
$\begin{array}{l}\text { Adjust the psychology spot and play the } \\
\text { first sound }\end{array}$ & $\begin{array}{l}\text { In the process of playing, we must always keep a clear head. This waking is } \\
\text { relative. This will not only enable you to devote yourself to music, express } \\
\text { Exclude all thoughts, } \\
\text { put all your soul into } \\
\text { music }\end{array}$ \\
$\begin{array}{l}\text { your own level of performance and the musical charm of your work, but also } \\
\text { enable you to control your own performance and flexibility. }\end{array}$ \\
$\begin{array}{l}\text { In the performance, we must let the command of the mind and the movement } \\
\text { of the leader, that is to say, think in the front of the action. } \\
\text { Nontrol feeling } \\
\text { Do matter what the situation may be, the performers should not panic and } \\
\text { that they don't change }\end{array}$ \\
$\begin{array}{l}\text { must remain calm. Try to keep yourself from being disturbed by these external } \\
\text { factors, or to focus your attention on the performance until the end of the } \\
\text { performance. }\end{array}$
\end{tabular}




\section{Practice of students' psychological control ability in the course of piano playing in piano group lessons}

The practice of students' psychological control ability cultivation for the piano performance during piano courses is mainly reflected in several aspects as shown in Table 5.

Table 5

Cultivation of Students' Psychological Control Ability in the Course of Piano Playing in Practical Practicing of Piano Collective Lessons

In the constant "forced" practice, students will gradually learn to face and overcome

The live experience

of teaching form the tension and fear of live performance. The person can gradually adapt to and learn to adjust the psychological state of public performance, so as to gradually cultivate a good psychological quality and have a certain degree of control of the psychological presence.

The use of diverse teaching content is not only conducive to the development of

Diversified training of teaching content students' overall musical ability structure, but also has an invaluable effect on the cultivation of students' practical ability, collaboration ability and psychological quality.

Students have many opportunities to perform on-the-spot performances. This

Flexible use of teaching methods enables students to gradually adapt to and overcome psychological cues such as tensions and rates of live performances in continuous practice, thereby helping students develop stable psychological control capabilities.

\section{The importance of training students' psychological control ability to piano teaching}

Piano teaching is distinguished from other subjects due to its distinctive features of highly technical, practical and empirical nature. It is, in a sense, a combination of skill teaching and psychological training. Both the teaching process and the learning process involve techniques and practices. Students gain skills and experience through repeated exercises. To cultivate students' sound psychological quality and stable on-the-spot psychological control ability, the most direct method is to give students as many public performance opportunities as possible, improve students' ability to adapt on the spot, and accumulate on-the-spot experience (Lundberg et al., 2018). In the case of collective teaching, students can easily have certain psychological suggestions and achieve common improvement through interaction, mutual confirmation, cooperation, and inspiration in the same learning environment.

\section{Conclusion}

Different subjects have different rules and characteristics of the cognitive psychology in individual activities. In any learning activities, a series of cognitive processes such as attention, perception, memory and thinking are involved. By utilization of such individual's cognitive psychological characteristics, proper guidance will lead to significant effects. Similarly, in the piano teaching, based on students' cognitive psychological characteristics and their cognitive rules, progressive and targeted teaching can definitely promote the substantial improvement of the piano teaching effect in colleges and universities. 


\section{References}

Bernal, S. B. (2018). Learning by teaching: Children's musical and emotional skills development through a piano teacher role. Music for and by Children, 178-188.

Colombo, B., \& Antonietti, A. (2017). The Role of Metacognitive Strategies in Learning Music: A Multiple Case Study. British Journal of Music Education, 34(1), 95-113. http://dx.doi.org/10.1017/S0265051716000267

Eitel A, Scheiter K. Picture or text first? explaining sequence effects when learning with pictures and text. Educational Psychology Review, 27(1), 153-80, http://dx.doi.org/10.1007/s10648-014-9264-4

Gelding, R. W., Thompson, W. F., \& Johnson, B. W. (2015). The pitch imagery arrow task: effects of musical training, vividness, and mental control. PloS One, 10(3), 1-10. http://dx.doi.org/10.1371/journal.pone.0121809

Guven, E. (2017). Levels of music performance anxiety and test anxiety of Turkish prospective music teachers in piano exams. International Journal of Music Education, 35(2), 154-164. http://dx.doi.org/10.1177/0255761415620530

Lundberg, J., Arvola, M., Westin, C., Holmlid, S., Nordvall, M., \& Josefsson, B. (2018). Cognitive work analysis in the conceptual design of first-of-a-kind systems - designing urban air traffic management. Behaviour \& Information Technology, 37(9), 904-925. https://doi.org/10.1080/0144929X.2018.1505951

MacRitchie, J. (2015). The art and science behind piano touch: A review connecting multi-disciplinary literature. Musicae Scientiae, 19(2), 171-190. http://dx.doi.org/10.1177/1029864915572813

Pike, P. D. (2014). The differences between novice and expert group-piano teaching strategies: A case study and comparison of beginning group piano classes. International Journal of Music Education, 32(2), 213227. http://dx.doi.org/10.1177/0255761413508065

Simones, L., Schroeder, F., \& Rodger, M. (2015). Categorizations of physical gesture in piano teaching: A preliminary enquiry. Psychology of Music, 43(1), 103-121.

Vandervert, L. (2016). The brain's rapid encoding of rule-governed domains of knowledge: A case analysis of a musical prodigy. Musical Prodigies: Interpretations from Psychology, Education, Musicology, and Ethnomusicology, 1(1). 245. http://dx.doi.org/ 10.1093/acprof:oso/9780199685851.003.0009

Zhou, Z. (2017). Discussion on Expression of Piano Opuses Based on Listeners' Psychological Laws. DEStech Transactions on Social Science, Education and Human Science, (ICSSTE), 35(22), 67. http://dx.doi.org/10.12783/dtssehs/icsste2017/9395 